\title{
0 ensino das ciências sociais e humanas na graduação em saúde coletiva: entre desafios $e$ oportunidades de transgressões
}

\section{Teaching social and human sciences in the collective health undergraduate course: between challenges and opportunities for transgressions}

\author{
Leny A. Bomfim Trad \\ (D) https://orcid.org/0000-0002-8762-4320 \\ E-mail: lenytradळyahoo.com.br

\section{Clarice Santos Mota ${ }^{\mathrm{a}}$} \\ (D) https://orcid.org/0000-0002-5168-7004 \\ E-mail: motaclariceळyahoo.com.br \\ Yeimi Alexandra Alzate López ${ }^{\mathrm{a}}$ \\ (D) https://orcid.org/0000-0001-6243-9367 \\ E-mail: yeimi79ळgmail.com \\ aniversidade Federal da Bahia. Instituto de Saúde Coletiva. \\ Salvador, BA, Brasil.
}

\section{Correspondência}

Leny Trad

Rua Basílio da Gama, s/n, Canela.

Salvador, BA, Brasil. CEP 40110-040.

\section{Resumo}

A implantação, em 2009, do curso de graduação em saúde coletiva (GSC) no Brasil e sua progressiva disseminação trouxe à tona velhas questões de ordem epistemológica, prática ou político-institucional relacionadas ao ensino das ciências sociais e humanas (CSH) nesse contexto e fez emergir outras. Sobretudo, esse novo curso recoloca no centro do debate a questão da identidade do campo da saúde coletiva ou as especificidades de seus objetos, atores/ agentes, conhecimentos e práticas. Afinal, tanto os projetos pedagógicos (perfil de egresso, estrutura curricular etc.) quanto seu modus operandi refletem uma dada concepção do campo. Propõe-se, neste artigo, discutir peculiaridades e desafios do ensino das CSH na GSC, considerando esses elementos a partir da análise da experiência de um curso em particular ou, melhor dito, do compartilhamento de vivências e impressões das autoras que integram seu corpo docente. Na primeira parte do texto, são esboçados argumentos em defesa da formação emancipatória e do conhecimento pluriuniversitário, apoiados no diálogo com Boaventura de Souza Santos. Entende-se que tais perspectivas são especialmente bem-vindas na GSC, a qual tem se revelado um espaço profícuo de experimentação de novas formas de agir na educação e na saúde.

Palavras-chave: Ensino das Ciências Sociais e Humanas; Graduação em Saúde Coletiva; Conhecimento Pluriuniversitário; Perfil de Egresso. 


\section{Introdução}

The implementation, from 2009, of the undergraduate course on collective health (GSC) in Brazil and its progressively dissemination has brought to the surface old epistemological, practical or politicalinstitutional issues, and led to the emergence of others. Above all, it should be noted that this new undergraduate course puts once again in the center of the debate the question of the collective health identity or, rather, the specificities of its objects, actors, knowledge and practices. After all, both the pedagogical projects (student's profile, curricular structure etc.) as its modus operandi reflect a given conception of the field. This article discusses the singularities and challenges of teaching social and human sciences in the undergraduate course in collective health, considering these elements through the analysis of a particular course or, better said, the sharing of experiences and impressions of the authors that integrate its academic staff. In the first part of the article, arguments are presented in defense of the emancipatory formation and multiuniversity knowledge, supported by the dialogue with Boaventura de Souza Santos. It is considered that such perspectives are especially welcome in undergraduate collective health, which has proved to be a useful space for experimenting new ways of acting in education and health.

Keywords: Social and Human Sciences Teaching; Undergraduate Course of Collective Health; MultiUniversity Knowledge; Student's Profile.
O ensino das ciências sociais e humanas (CSH) na saúde coletiva no Brasil se expandiu e se diversificou ao longo de três décadas, abrangendo os vários níveis de formação (Canesqui, 2007). No que se refere à graduação, as disciplinas da área eram ofertadas para cursos diversos da área da saúde. A partir de 2009, com a implantação dos primeiros cursos de graduação em saúde coletiva (GSC) e sua progressiva expansão, esse quadro se modificou.

Parece que os questionamentos iniciais quanto à "pertinência" da criação do curso de CSG foram superados e os dissensos iniciais cederam lugar a uma adesão crescente a esse projeto por parte das instituições de ensino superior, notadamente aquelas que já possuíam programas de pósgraduação na área. Por outro lado, os processos de implantação e implementação de novos cursos pelo país afora têm revelado uma série de desafios, destacando-se aspectos relacionados à definição de suas diretrizes, conformação dos projetos pedagógicos e seu reconhecimento legal. São especialmente evidentes as preocupações com as perspectivas de incorporação dos novos profissionais no mercado de trabalho.

Cabe ressaltar que a definição das diretrizes do curso compõe, com o projeto pedagógico e o perfil dos docentes/discentes, elemento estruturante no processo de conformação da identidade do graduado(a) em saúde coletiva e suas competências. Assim, eles são também aspectos centrais na discussão sobre a participação das ciências sociais nessa nova graduação. No caso das diretrizes, trata-se de um marco nacional que, em princípio, norteia todos os cursos. Chama atenção nesse documento-base a incorporação bastante tímida das ciências sociais e humanas em saúde (CSHS) e, sobretudo, uma ênfase em conhecimentos e habilidades no âmbito da gestão de sistemas e serviços de saúde.

Pode-se presumir, no entanto, que os conhecimentos desse campo serão especialmente requeridos para lograr o perfil de egresso descrito no artigo 3: “o graduado em saúde coletiva terá formação generalista, humanista, crítica, reflexiva, ética e transformadora" e deve ser capaz de atuar "no desenvolvimento científico e tecnológico da área de saúde coletiva 
com responsabilidade social e compromisso com a dignidade humana, cidadania e defesa da democracia, do direito universal a saúde e do Sistema Único de Saúde" (Brasil, 2018).

No mesmo artigo, há destaque para a "determinação social do processo saúde-doença”, indicada como um elemento básico a ser considerado na formação do graduando em saúde coletiva.

Quanto aos projetos pedagógicos, constatase que há variação considerável entre os cursos existentes. Tal diversidade se aplica também à contribuição das CSH nos projetos como um todo ou, particularmente, nas grades curriculares - um dado que, assim como ocorre nos demais níveis de formação, reflete especificidades institucionais, além da disponibilidade e dos perfis dos profissionais envolvidos (Canesqui, 2007). Se a ausência de um projeto pedagógico comum não é por si só um aspecto preocupante, a tendência de afirmação de uma visão pragmatista, que parece prevalecer nos debates sobre a formação deste profissional, revelase especialmente problemática.

Em outras palavras, trata-se de uma concepção de formação que, no limite, potencializa o "saber fazer" em detrimento do "saber ser", optando-se muitas vezes pelas perspectivas mais conservadoras de formação por competências. Reforça-se, desse modo, uma tendência que se instaurou no Brasil a partir das reformas educativas da década de 1990, que passaram a realçar "o ideário da 'polivalência', da 'qualidade total', das 'competências', do 'cidadão produtivo' e da 'empregabilidade'”, deixando no esquecimento a referência à "educação integral”, "laica”, "unitária" e "emancipadora' (Frigotto; Ciavatta, 2003, p. 46). Soma-se a isso, como bem coloca Boaventura de Sousa Santos (2008, p. 28), uma visão excludente e hierarquizada da produção de conhecimento, "predominantemente disciplinar, cuja autonomia impôs um processo de produção relativamente descontextualizado em relação às premências do quotidiano das sociedades".

No tocante ao perfil dos docentes, predomina aqui um elenco de doutores mais jovens, que foram incorporados aos quadros das universidades públicas graças ao Programa de Apoio a Planos de Reestruturação e Expansão das Universidades Federais (Reuni). Mantendo certa convergência com o que aconteceu nos Estados Unidos, conforme Norman (2011), temos aqui uma geração na qual se mesclam professores que fizeram seu doutorado em programas de saúde coletiva, geralmente com foco nas ciências sociais, e outros cuja formação é originalmente nessa área.

A partir dessas premissas iniciais, propõe-se, neste artigo, desenvolver uma reflexão sobre os desafios do ensino das CSH na CSG, apresentando, em um primeiro momento, princípios básicos de uma concepção de ensino ou formação que se contraponha a uma ideia instrumental do processo de ensinoaprendizagem. Para tanto, esta reflexão inicial resgata a noção de educação emancipadora presente no pensamento freiriano e segue, concentrando-se no diálogo com Boaventura de Sousa Santos (2008, 2009) em duas direções principais. A primeira assinala as principais críticas ao modelo de ensino, produção de conhecimento e universidade dominante no mundo ocidental. A segunda procura extrair das proposições desse autor, em defesa de um ensino pluriuniversitário ou de uma nova institucionalidade que oriente as relações entre universidade e sociedade (Santos, 2008), fontes de inspiração na construção de projetos pedagógicos inovadores na CSG.

Nas outras duas seções do artigo, apresenta-se um relato da experiência do curso de CSG do Instituto de Saúde Coletiva (ISC) da Universidade Federal da Bahia (UFBA), um dos pioneiros no Brasil. Mais especificamente, compartilham-se aqui aspectos relativos à participação ou contribuição das CSH, seja do ponto de vista das disciplinas, dos temas e dos enfoques contemplados, seja na definição de questões estratégicas relacionadas ao projeto pedagógico, incluindo pontos sobre a escolha dos campos de prática.

Ao tratar do tema da estrutura curricular, virá à tona a preocupação com lacunas em termos de disciplinas ou outras atividades especificas das CSHS, o que permitiria promover uma formação teórica e metodológica mais sólida na área. Esse aspecto foi interrogado em uma pesquisa coordenada por Minayo (1997) cujos participantes apontaram a necessidade de demarcação de um conhecimento básico das ciências sociais que, por um lado, preservasse a identidade da área e, por outro, permitisse a exploração de objetos 
fronteiriços reconhecidos como essenciais para a teoria e a prática da saúde coletiva. Foi ressaltado, no entanto, que a oferta de conteúdos considerados indispensáveis para promover o aprofundamento de modelos teóricos e conceituais da área poderia se dar sob outras formas além das disciplinas (Minayo, 1997).

A delimitação do perfil do egresso será outro aspecto problematizado no texto. Trata-se de um elemento estruturante do curso como um todo e que tem se revelado um ponto de atrito nos debates acerca das diretrizes curriculares e da formulação ou revisão de projetos pedagógicos. Observa-se aqui a tendência a restringir o horizonte de atuação do egresso aos sistemas e serviços de saúde. Certas peculiaridades do campo da saúde coletiva - as interfaces entre saberes e práticas científicas e técnicas, entre o social e o biológico e as fortes imbricações entre o campo e a burocracia estatal do setor saúde (Luz, 2011; Nunes, 2006) - ajudam a entender esse dado. Por outro lado, estabelecer um limite muito estrito para pensar o espaço de atuação do graduado em saúde coletiva contraria a chamada concepção ampliada de saúde, muito cara ao campo.

O incômodo diante da situação referida suscitou a mobilização e a criatividade de alguns docentes das CSHS que atuam no curso, oportunizando a realização de atividades que transcendem a esfera da gestão, do planejamento, da avaliação etc. nos serviços de saúde. É precisamente uma iniciativa dessa natureza, levada a cabo na disciplina Práticas Integradas em Saúde por uma das autoras deste artigo, que se descreve na última parte do texto.

Vale registrar que este artigo não propõe realizar uma análise exaustiva da experiência em foco, nem tem a pretensão de expressar a visão do coletivo da área que atua na instituição. Seu conteúdo reflete algumas vivências e pontos de vista das três autoras do texto, as quais integram o quadro de docentes das CSHS do ISC-UFBA. Oportunamente, são incorporados ao longo da discussão, dados extraídos de uma pesquisa recente que traçou um perfil dos atores e das práticas (de pesquisa, ensino e extensão) filiadas ao campo das CSHS em programas de pós-graduação em saúde coletiva (PGSC) (Trad et al., 2018).

\section{A formação emancipatória e o conhecimento pluriuniversitário: subsídios para projetos pedagógicos e prática docente}

Tanto para Paulo Freire quanto para Boaventura de Sousa Santos, o currículo é entendido como artefato político de organização e desenvolvimento de um projeto pedagógico, cujos objetivos visam a promoção dos sujeitos e a formação para o exercício da cidadania (Santiago, 2012). Os projetos pedagógicos dos cursos (conteúdo e métodos), além de contemplarem informações, dados ou fatos reconhecidos como conhecimento científico, devem explicitar opções axiológicas, reflexões éticas e atitudes que se traduzam em marcas identitárias na relação homem/mundo (Santiago, 2012).

Em consonância com a proposição de Gadotti (2012), é possível reconhecer a necessidade de formar trabalhadores de saúde polivalentes, autônomos e que sejam capazes de se adaptar às novas configurações do mundo do trabalho, desde que não se negligencie o compromisso com a formação de sujeitos críticos. Trata-se de afirmar a defesa de uma educação emancipadora ou, melhor dito, emancipatória, considerando as nuances conceituais, conforme sinaliza esse autor:

"Emancipadora" refere-se mais à ação, educação, processo, práxis, prática, e "emancipatória" referese mais à concepção, ideal, à teoria, princípios, avaliação, currículo, ética, potencial, racionalidade, competência, conceito, concepção, perspectiva. Por "perspectiva emancipatória" da educação entende-se a visão de que os processos educativos precisam estar comprometidos com uma visão de mundo transformadora, inconformada com um mundo injusto e insustentável em que vivemos. Por isso, uma perspectiva emancipatória da educação e do trabalho deve desenvolver a capacidade de pensar criticamente a realidade e promover a justiça e a solidariedade, fundada na ética, e respeitando a dignidade e a autonomia do educando. (Gadotti, 2012, grifos do autor) 
Boaventura de Sousa Santos (2009) é outro interlocutor importante nesse debate sobre educação emancipatória. Ele entende que a construção de um projeto educativo emancipatório implica uma mudança radical de racionalidade na produção e difusão de conhecimento. É preciso, para isso, admitir os limites da racionalidade científica moderna, pela qual problemas de ordem social e/ou política foram convertidos em problemas técnicos. Trata-se de recusar uma ciência que exacerba o valor da sua “aplicação técnica" ou "edificante”, uma "na qual o conhecimento é sempre usado em situações concretas e quem o manipula está "existencial, ética e socialmente comprometido com o impacto da aplicação" (Santos, 2009, p. 22).

Seguindo uma vertente de transformação radical, Santos (2009) propõe que a sala de aula se transforme em um campo de possibilidades de conhecimento que estimule professores e alunos a fazer escolhas, que podem ser conflitantes e transitórias. Para além das ideias, tais escolhas devem ser influenciadas também pelas emoções, pelos sentimentos e pelas paixões, conferindo, assim, aos conteúdos curriculares sentidos inesgotáveis (Santos, 2009, p. 19).

É justamente ao pensar na questão das escolhas no âmbito da docência na CSG, notadamente daquelas que refletem uma dada concepção de ensinoaprendizagem, que o diálogo com esse autor se revela especialmente oportuno - em primeiro lugar, quando ele nos lembra que as profundas transformações que vêm sendo observadas nas relações entre conhecimento e sociedade, e nas concepções sobre ambos nas últimas décadas, impõem novos desafios à universidade, particularmente à universidade pública.

Importa dar visibilidade, por ora, a alguns argumentos apresentados por Santos para criticar o modelo de universidade que tem prevalecido até aqui e, ao mesmo tempo, propor perspectivas de inovação, com vistas à construção da "universidade do século XXI” (Santos, 2008). Começando pelas transformações em curso, relacionadas à concepção e produção do conhecimento, suas críticas se dirigem especialmente a ideias e comportamentos claramente orientados pelos princípios da hegemonia, endogenia e hierarquia.

Sua análise chama atenção para um modelo de produção de conhecimento científico que moldou a organização universitária e o ethos universitário no século XX, mas que, no seu entender, vem sendo desestabilizado nos últimos anos. Nele, os investigadores determinam os problemas a serem resolvidos e sua relevância, assim como as metodologias e os planos de pesquisa. O caráter endógeno desse modelo de produção, a hierarquização de saberes que contrapõe universidade e sociedade - excluindo esta última de processos decisórios significativos - e o baixo potencial de aplicabilidade do conhecimento produzido são os alvos principais da sua crítica:

Prevalece assim um conhecimento homogéneo e organizacionalmente hierárquico na medida em que agentes que participam na sua produção partilham os mesmos objetivos de produção de conhecimento, têm a mesma formação e a mesma cultura científica e fazem-no segundo hierarquias organizacionais bem definidas. É um conhecimento assente na distinção entre pesquisa científica e desenvolvimento tecnológico e a autonomia do investigador traduz-se numa certa irresponsabilidade social deste ante os resultados da aplicação do conhecimento. Ainda na lógica deste processo de produção de conhecimento universitário a distinção entre conhecimento científico e outros conhecimentos é absoluta, tal como o é a relação entre ciência e sociedade. A universidade produz conhecimento que a sociedade aplica ou não, uma alternativa que, por mais relevante socialmente, é indiferente ou irrelevante para o conhecimento produzido. (Santos, 2008, p. 40)

Notem que, em outro momento do artigo, evocamos o mesmo autor para destacar os limites de uma ciência pautada na supervalorização da "aplicação técnica" e reforçar a defesa de uma formação emancipatória (Santos, 2009). No entanto, aqui ele ressalta a necessidade de levar-se em conta o potencial de aplicação do conhecimento produzido na universidade. Essa aparente contradição parece se dissolver quando se observa que, na sua concepção, o compromisso com a aplicabilidade não pode prescindir de uma mudança radical no modelo de produção do conhecimento universitário, implicando diversificação de atores, espaços e racionalidades. De fato, ele propõe uma 
ruptura com a lógica universitária e a adesão a uma perspectiva pluriversitária. Nesta, prevalece uma produção contextual do conhecimento que se desenvolve por meio de um processo compartilhado - entre pesquisadores e potenciais interessados -, abrangendo formulação de problemas, definição de critérios de relevância etc. Entende-se que a nova configuração proposta se assenta no pressuposto de valorização de práticas que fomentem a construção de sujeitos críticos e empoderados, capazes de analisar uma dada realidade e posicionar-se com independência diante dela.

Trata-se de um modelo especialmente desafiador para a comunidade científica. Por um lado, ele favorece modos de organização mais abertos, menos rígidos e hierárquicos - e, no seu âmago, subverte a relação historicamente estabelecida entre ciência e sociedade, que "deixa de ser um objeto das interpelações da ciência para ser ela própria sujeita de interpelações à ciência” (Santos, 2008, p. 41-42). Por outro lado, ao promover o "diálogo ou confronto com outros tipos de conhecimento", se configura uma tal heterogeneidade que "não só desestabiliza a especificidade institucional atual da universidade, como interpela a hegemonia e a legitimidade desta na medida em que a força a avaliar-se por critérios discrepantes entre si" (Santos, 2008, p. 42).

Embora reconheça que o conhecimento pluriuniversitário tem se expandido ou se concretizado principalmente no âmbito das parcerias universidade-indústria, prevalecendo assim um interesse mais mercantil, Santos (2008) destacou a existência de experiências promissoras de parcerias entre pesquisadores e grupos diversos da sociedade civil em países centrais e semiperiféricos, nas quais prevalecem os princípios da solidariedade e da cooperação. As novas configurações do ativismo contemporâneo parecem ter papel determinante na emergência e difusão dessa vertente.

Ao mesmo tempo, torna-se imperativo relativizar a avaliação do autor de que o modelo universitário hegemônico vem perdendo fôlego. Tendo em conta que o livro referido foi publicado no final da primeira década do século XXI, provavelmente seu otimismo refletia a conjuntura da época, bastante diferente da atual onda conservadora que vem se disseminando pelo mundo afora. Tal ressalva não reduz, decerto, o potencial de contribuição das proposições apresentadas por Santos.

Do ponto de vista da questão em foco neste artigo - as contribuições das ciências sociais para a formação graduada em saúde coletiva - destacase que a noção de conhecimento pluriuniversitário nos instiga a pensar na necessidade de subverter uma dada visão de objeto e campo de atuação da saúde coletiva que, no limite, produz um efeito excludente ao não contemplar de forma plena questões e demandas sociais contemporâneas, a exemplo das lutas de grupos subalternizados em prol do reconhecimento de sua identidade e seus direitos à saúde e à vida. É preciso considerar também o necessário combate ao epistemícidio, que relega ao esquecimento saberes tradicionais que poderiam se contrapor a alguns efeitos nocivos da medicalização em curso.

Convém esclarecer que esse movimento se revela na nossa prática de docência na CSG em uma fase embrionária. Desse modo, a despeito da nossa identificação com os princípios do "conhecimento pluriuniversitário", ele se apresenta, neste momento, mais como uma "imagem-objetivo" a ser alcançada.

\section{ensino das ciências sociais $e$ humanas na graduação em saúde coletiva: os atores e as mediações entre o desejável e o possível}

O curso de GSC da UFBA iniciou suas atividades em 2009, com um corpo docente constituído majoritariamente por docentes aprovados nos primeiros concursos vinculados ao projeto Reuni, cujos perfis contemplavam os três eixos disciplinares da saúde coletiva - política, planejamento e gestão (PPG), CSHS, epidemiologia. Esse quadro foi se ampliando ao longo do tempo, graças à criação de vagas de reposição em função de aposentadorias. No que concerne ao corpo docente responsável especificamente por disciplinas das CSHS, temos hoje um total de nove professores, sendo sete mulheres e dois homens, brancos(as) ou pardos(as).

Enquanto o predomínio feminino parece refletir o perfil dominante na saúde coletiva desde sua criação, a ausência de pretos (pretas) nesse conjunto 
revela a dificuldade em superar a inequidade racial que marca, em geral, a ocupação de quadros universitários. Espera-se que essa configuração se modifique à medida que a recente implantação da política de cotas na pós-graduação no Brasil repercuta em concursos futuros voltados ao ensino superior e se expresse na diversificação do perfil de aprovados. No caso do ISC-UFBA, foi visível na seleção de mestrado e doutorado de 2018, quando se inaugurou o critério de cotas para o ingresso na pósgraduação, a ampliação da representação de pretos e pretas dentre os aprovados para ambos os cursos.

No tocante à formação dos professores, a maioria (seis) tem formação graduada em ciências sociais ou humanas (sociologia, antropologia e psicologia), e três em cursos da saúde (medicina e fisioterapia). Quanto à pós-graduação, destacando-se o doutorado, temos a seguinte distribuição: formação em programas da saúde coletiva com área de concentração em ciências sociais e saúde ou similar (cinco) e em programas das ciências sociais (sociologia ou antropologia), prevalecendo à ênfase na saúde (quatro).

A partir da nossa experiência, é possível considerar que as ambiguidades e desafios que se revelam ao discutir a questão da "identidade" dos docentes das CSHS e as diferenças que aparecem quando discutimos sobre que conhecimentos ou enfoques da nossa área devem ser privilegiados no currículo da CSG ou nas escolhas da metodologia de ensino refletem múltiplas trajetórias de formação e atuação e sua imbricação com o percurso de construção do campo.

Convém evocar aqui a ideia de "gerações". Uma perspectiva interessante para analisar as mudanças geracionais no campo das CSHS consiste em distinguir os docentes e pesquisadores segundo sua participação nos momentos de constituição, institucionalização e consolidação do campo da saúde coletiva e da área de CSHS (Ianni et al., 2014). Essa foi a lógica adotada pela pesquisa coordenada por Trad et al. (2018) ao traçar o perfil dos quadros da área inseridos em programas de PGSC entre 2004 e 2017. O universo de docentes/pesquisadores investigados foi dividido em três grupos: geração histórica, formada pelo grupo dos fundadores (décadas de 1980 e 1990); geração intermediária, de 2000 a 2008 , composta por pesquisadores que despontaram no cenário acadêmico a partir da década de 2000 e foram progressivamente assumindo posições de liderança no campo das CSHS; e nova geração, que ingressou a partir de 2009, com o Reuni.

Aplicando-se a mesma tipologia para traçar o perfil geracional dos docentes da CSHS do curso em foco, é possível considerar que, dos nove, quatro situam-se na geração intermediaria e cinco situamse na geração nova ou “geração Reuni” de docentes, sendo estes últimos os principais responsáveis pela docência na CSG.

Entende-se que falar em gerações significa não apenas analisar o eixo temporal no qual se enquadram as experiências dos docentes, levando em consideração o momento histórico de inserção dentro dos programas de pós-graduação e graduação, mas também a temporalidade no processo de consolidação do Sistema Único de Saúde (SUS). Parte-se do pressuposto de que as especificidades de cada geração surgem não só a partir das diferenças na formação de base e identidade profissional, mas também desse tempo histórico de atuação. Acreditase que esse perfil traz diferentes desafios para as práticas de ensino, pesquisa e extensão, bem como para o exercício da interdisciplinaridade.

O desenho curricular do curso de GSC do ISCUFBA seguiu uma lógica diferente do programa da pós-graduação da instituição, que é estruturado por áreas de concentração e reflete, em grande medida, o perfil de formação/atuação dos docentes credenciados. No caso da graduação, o projeto pedagógico, notadamente a estrutura curricular, foi pensado considerando as especificidades do curso e a leitura sobre as necessidades e demandas de pessoal do principal setor de ocupação do campo: a saúde, mais especificamente o SUS. Procurou-se, assim, promover um ensino o mais interdisciplinar possível, que permitisse que o aluno tivesse realmente uma formação ampla dentro do campo de saberes que integram a saúde coletiva e conseguisse responder às demandas sociais e dos serviços. Não obstante, do ponto de vista dos conteúdos privilegiados, observase a primazia do núcleo de PPG, dado que contrasta com a realidade da PGSC, na qual se evidenciou, na oferta de disciplinas, certa concentração na epidemiologia (Nunes et al., 2010). 
Assim, no momento da implantação, a preocupação central era estruturar o próprio curso, e não as áreas em si. 0 esforço do grupo de professores das CSHS concentrou-se, então, na construção ou atualização de ementas e programas dos componentes curriculares, tendo como meta a interdisciplinaridade, em conformidade com o projeto político-pedagógico do curso já existente. Nele, os conteúdos da área são contemplados em um eixo temático transversal, denominado Sociedade, Cultura e Saúde (SCS), e em três disciplinas de caráter mais introdutório, oferecidas no primeiro ano: Introdução às Ciências Humanas e Sociais em Saúde, Teorias Sociais em Saúde e Saúde, Doença e Cuidado. As quatro disciplinas que integram o eixo SCS são oferecidas em quatro semestres consecutivos a partir do segundo ano de curso e visam o aprofundamento de conceitos, temas e métodos da área.

$\mathrm{Na}$ abertura do eixo SCS, privilegia-se o debate sobre temas ou categorias que guardam relação mais direta com a determinação social do processo saúdedoença e os múltiplos indicadores da desigualdade social e seus efeitos, destacando-se a vulnerabilização de determinados grupos sociais. Nos demais, os focos se voltam para questões mais diretamente relacionadas com os serviços ou as práticas de saúde. Constata-se, nesse caso, que o desafio maior consiste em trazer aportes teóricos ou metodológicos das ciências sociais que possam contribuir para uma análise crítica dos temas tratados.

Convém assinalar que, como se percebeu ao mapear as disciplinas de CSHS na PGSC (Trad et al., 2018), não é tarefa fácil tipificar as disciplinas, considerando a taxonomia que vem sendo adotada pela Coordenação de Aperfeiçoamento de Pessoal de Nível Superior (Capes) nos processos de avaliação dos programas de pós-graduação, que compreende categorias teóricas, metodológicas ou temáticas. Mesmo entre as autoras do artigo, não se conseguiu chegar a um consenso na classificação das disciplinas mencionadas. Os debates travados contribuíram para reforçar a percepção da fragilidade dessa lógica classificatória, especialmente quando se trata de estabelecer uma distinção entre disciplinas teóricas ou temáticas.

De fato, trabalhar conceitos básicos e, principalmente, aqueles mais complexos pela reflexão sobre temas concretos, próximos da realidade dos alunos, tem se revelado, ao longo da nossa experiencia na GSC, uma estratégia fundamental para favorecer o aprendizado. Além disso, é importante levar em conta peculiaridades do curso que afetam diretamente na organização dos conteúdos, na metodologia ou no desempenho dos alunos. Destaca-se aqui o fato de tratar-se de um curso noturno, no qual a maioria dos alunos vem para as aulas depois de sua jornada de trabalho, assim como as limitações na carga horária das disciplinas. Temas que, em um curso de graduação em ciências sociais, são abordados ao longo de um semestre, aqui precisam ser condensados em uma disciplina de 34 horas. Embora essa mesma dificuldade se observe na nossa pós-graduação, ela se agudiza na graduação.

Talvez por esse motivo, aliado à pretensão antes referida de fortalecer o enfoque interdisciplinar do curso de graduação, progressivamente tem se afirmado a faceta mais temática na definição dos programas das disciplinas das CSHS que integram a grade curricular. Essa é uma tendência que acompanha o movimento de mudança observado no perfil das disciplinas da PGSC nos últimos anos, passando de certa concentração em disciplinas teóricas para uma ampliação significativa de disciplinas temáticas. Em tese, esse tipo de disciplina pode favorecer a adoção de abordagem interdisciplinar, na medida em que requer a conjunção de conhecimentos diversos para abordar os múltiplos aspectos relativos a um dado tema ou problema social.

A tendência referida é evidente no subcampo das CSHS. No caso da pesquisa, desde a inclusão da metodologia de grupos temático (GT) nos congressos da área, se evidenciou uma escassa representação de GT disciplinares (que valorizassem nos seus enunciados a disciplina - sociologia, antropologia, história etc.), prevalecendo claramente o foco em categorias ou temas - gênero, corpo, biopoder etc. (Trad, 2012). Olhando especificamente para o ensino, um estudo recente aponta uma preocupação das novas gerações da área com a valorização da interdisciplinaridade nos processos de formação em saúde coletiva, incluindo concepções, desenho das atividades e operacionalização (Ianni et al., 2014).

Mas, não há dúvidas de que a formação téorico-conceitual é bastante incipiente. Dos sete componentes curriculares em CSHS, apenas um, 
Teorias Sociais em Saúde, propõe uma discussão mais aprofundada de aspecto teóricos. Dessa forma, tende-se a tratar de modo relativamente superficial as contribuições de autores clássicos ou contemporâneos das ciências sociais para o campo da saúde. 0 curso não contempla disciplinas obrigatórias de metodologia. A formação em pesquisa é abordada nas disciplinas (1 e 2) de construção do trabalho de conclusão do curso, que são oferecidas no último ano. É nesse momento que tanto os discentes quanto os docentes percebem os reflexos das lacunas de conteúdos metodológicos.

$\mathrm{Na}$ fase de criação do curso, acreditava-se que os discentes da graduação seriam incorporados desde o primeiro momento nos programas integrados de pesquisa do ISC, o que lhes garantiria uma formação consistente nesse segmento. Entretanto, em função principalmente da condição de trabalhador da maioria dos alunos, poucos têm exercido a prática de iniciação científica no interior dos referidos programas. A oferta da disciplina optativa Introdução à Metodologia Científica tem contribuído, bem como o esforço dos docentes em incorporar questões relativas à pesquisa no conjunto das disciplinas obrigatórias, para minimizar essa lacuna.

Alguns anos após o início do curso, e após o ingresso de novos professores das ciências sociais em saúde (CSS), foi possível estabelecer um diálogo mais denso sobre o papel das CSHS na formação em saúde coletiva. O grupo construiu uma matriz de competências, definindo que conceitos, autores e enfoques era preciso assegurar na formação. Apesar de certas ressalvas, entendeu-se que era necessário definir competências esperadas para o egresso, especificando-se que, ao final do curso, aluno deve ser capaz de: (1) compreender o processo histórico de construção social do setor da saúde; (2) analisar o processo de determinação social das condições, dos estados e das práticas de saúde-doença-cuidado; (3) analisar as concepções e práticas de saúde enquanto práticas sociais inseridas em contextos macro e microestruturais; (4) identificar necessidades sociais em saúde de grupos sociais distintos, favorecendo processos participativos de definição de necessidades prioritárias; (5) dialogar com o saber do outro para argumentar, negociar e pactuar práticas de saúde, assim como de construção e compartilhamento de saberes em saúde; e (6) analisar as respostas sociais organizadas existentes quanto às necessidades sociais em saúde, colaborando para sua orientação, especialmente no que se refere à relação Estado-sociedade.

Espera-se que o eixo possa também desenvolver habilidades no estudante, como: (1) adotar práticas investigativas adequadas para identificar experiências, concepções e práticas de saúde-doençacuidado contextualizadas histórica e socialmente; (2) identificar e analisar práticas institucionais e não institucionais do processo saúde-doençacuidado, tanto no que se refere aos seus aspectos estruturais quanto aos aspectos relacionais (interações sociais); e (3) realizar investigações em saúde coletiva orientadas por conceitos das CSS - a exemplo da experiência de enfermidade e cuidado, de itinerários terapêuticos, de setores assistenciais, de modelos explicativos e redes sociais, do trabalho e da interseccionalidade, dentre outros -, de modo a produzir dados e análises pertinentes à organização das práticas e do trabalho em saúde, dos modelos de atenção e das políticas em saúde. Algumas atitudes também devem ser estimuladas no processo de ensino-aprendizagem, como o exercício da escuta sensível e respeitosa do Outro, a postura crítica e dialógica e a vigilância epistemológica.

Há pouco mais de dois anos, os professores que integram o Núcleo Docente Estruturante do CGSC decidiram iniciar um processo de reformulação de currículo, almejando torná-lo mais interdisciplinar e mais focado na dimensão prática, em detrimento da teórica. Foi decidido conferir mais protagonismo ao componente curricular Práticas Integradas em Saúde Coletiva, que é transversal em todos os semestres e passaria a ser a espinha dorsal do curso. Trata-se de um componente curricular totalmente prático, voltado para atividades em comunidade no âmbito da gestão ou nos serviços de saúde.

Foram definidos objetivos/focos específicos para cada ano de curso (à exceção do quarto, que é dedicado principalmente à elaboração do trabalho de conclusão), privilegiando atividades consideradas básicas no trabalho em saúde coletiva: (1) a realização de uma análise de situação de saúde, caracterizando o perfil de saúde-doença de uma população e os 
principais problemas relacionados aos serviços de saúde em um dado território; (2) o desenvolvimento de estratégias de promoção da saúde, refletindo criticamente sobre os modelos de atenção e propondo intervenções sobre problemas do estado de saúde e/ ou dos serviços de saúde identificados em um dado território; e (3) ações de gestão, monitoramento e avaliação em saúde, oportunizando a vivência e discussão sobre os processos de gestão no nível técnico-operacional nos âmbitos local e distrital.

Em cada um desses momentos, é possível apontar contribuições específicas de conhecimentos e ferramentas das CSHS. No momento inicial, de análise de uma dada situação de saúde, os componentes curriculares da área permitem examinar os processos de determinação social, a distribuição desigual de recursos, serviços e oportunidades e os mecanismos que geram essas disparidades sociais, que resultam em iniquidades de saúde. É de fundamental importância que o aluno saiba reconhecer e analisar necessidades sociais de saúde para refletir que nem sempre as intervenções propostas por programas ou políticas de saúde de fato atendem às necessidades das pessoas. Mesmo no terceiro ano da formação, cujo foco principal é a gestão dos serviços e sistemas de saúde, as CSHS contribuem na identificação e reflexão sobre as relações de poder dentro dos serviços de saúde, a burocracia, as dificuldades de acesso e os desafios da integralidade da rede e da articulação dos serviços de saúde.

Por outro lado, dentro da nova arquitetura curricular, na qual a dimensão prática é estruturante do processo de formação, espera-se que prevaleça uma configuração na qual as diferentes disciplinas subsidiem os projetos ou atividades da prática, agregando conceitos e conteúdos de forma articulada. É um desafio constante manter esse elo entre os componentes curriculares e, sobretudo, exercitar a produção coletiva de sentido.

Há a expectativa de que as mobilizações em torno da prática possam fomentar entre docentes e discentes olhares interdisciplinares que potencializem a compreensão da saúde em meio a processos sociais, culturais, políticos e ideológicos. Contudo, empreender esse exercício em um curso organizado por disciplinas tem demandado muitos esforços. É igualmente desafiadora a busca de diálogos e parcerias, bem como o diálogo com gestores do SUS, trabalhadores da saúde e movimentos sociais, considerando as diferentes racionalidades em tela, as peculiaridades na definição de agendas (prioridades, cronogramas etc.).

Por certo, o processo de escolha das atividades práticas e seus desdobramentos inclui a escuta aos alunos e leva em conta as demandas dos serviços de saúde e, em certa medida, de outros atores comunitários. A articulação entre o curso de GSC e a Residência Multidisciplinar em Saúde da Família do ISC tem favorecido a inserção mais orgânica dos discentes nos distritos sanitários de atuação desta.

Em qualquer caso, a viabilização de campos de prática em um curso noturno constitui um desafio permanente. Prevalece nos serviços de saúde, assim como em outros espaços que poderiam ser pensados para a realização da prática, o funcionamento diurno. Do lado dos discentes, temos uma maioria de trabalhadores que não tem disponibilidade para participar da prática diurna. Por fim, quando se cogita desenvolver atividades noturnas em contextos comunitários, privilegiando ações extramuro no território, os problemas crônicos da violência urbana e a fragilidade da segurança na cidade impõem-se como um obstáculo significativo.

Todos os desafios apontados têm sido objeto das reuniões semanais e semestrais de planejamento e avaliação do curso.

\section{Desvelando novos territórios e possibilidades de práticas em saúde coletiva}

Ao tentar romper com o formato disciplinar e apostar nas práticas em territórios como eixo central da formação, surgem novos desafios e questionamentos: que territórios podem proporcionar aprendizados significativos? O que levamos ao território e o que pretendemos aprender com ele? De que forma vamos construir conhecimento com as pessoas em vez de levar informação para as pessoas?

Refletindo sobre essas questões, considerou-se oportuno compartilhar neste artigo uma experiência vivenciada em quatro semestres do componente 
curricular Práticas Integradas em Saúde Coletiva, sob a coordenação de uma das autoras deste artigo. A proposta foi concebida considerando três objetivos principais: valorizar a diversificação de atores, espaços e racionalidades na produção do conhecimento (Santos, 2009); contribuir para ampliar o olhar sobre o complexo relacional saúdedoença-cuidado; e desenvolver ações no território com ênfase na promoção da saúde (tema central do terceiro ano do curso).

A prática ocorreu em Ilha de Maré, que, embora seja parte do município de Salvador, parece apartada da capital. Os 50 minutos de travessia a barco nos conduziram a um território inteiramente diferente, com uma população de 6.000 habitantes cujas fontes de subsistência são a pesca e a mariscagem, e que tem um ritmo próprio de conduzir a vida.

Iniciamos as idas a Maré no mesmo barco utilizado pelos trabalhadores da saúde para chegar diariamente à ilha. Assim, no próprio trajeto, começamos a descortinar algumas facetas daquele território, incluindo sua vulnerabilidade, agravada pela escassez de serviços básicos, como saneamento básico e coleta de lixo regular. Os moradores da ilha não contam com serviços de emergência e o território possui apenas uma Unidade de Saúde da Família (USF).

A fim de estabelecer uma relação de confiança com a comunidade, passamos a frequentar a escola e a unidade de saúde de forma regular. Os agentes comunitários da USF, moradores de Ilha de Maré, eram atores-chave para estabelecer vínculo com os moradores, de modo que as visitas domiciliares eram fonte de grandes aprendizados. O diálogo com os moradores permitiu perceber um sentimento de abandono do poder público e de não pertencimento ao território. A identidade quilombola era frequentemente associada a atraso cultural e, não raro, crianças e jovens relatavam o desejo de sair daquele lugar diante da ausência de perspectivas ou dos problemas socioambientais.

A escola municipal de Ilha de Maré também se tornou lócus privilegiado de construção de conhecimento, contrariando a perspectiva de que a atuação do sanitarista se restringe ao serviço de saúde. Desenvolvemos estratégias de articulação entre os profissionais da USF e professores e dirigentes da escola, realizando reuniões conjuntas, de modo a estabelecer redes de cooperação. A escuta e observação do ambiente escolar contribuiu para fortalecer uma visão ampliada do processo saúdedoença-cuidado e estimulou o profissional de saúde a fomentar parcerias para a identificação e superação dos problemas da comunidade.

A oficina de grafite na escola resultou na pintura do muro, com desenhos e frases que retrataram identidade e pertencimento quilombola; a oficina de bonecas abayomi contribuiu para refletir sobre a história da escravidão e as estratégias de enfrentamento do racismo; a oficina de turbantes e a roda de conversa com as mães sobre os cabelos das crianças despertaram novos olhares sobre a estética negra.

Os alunos dessa escola mencionaram que a universidade aparecia para eles como um local distante e inatingível. Então os convidamos para passar um dia na UFBA. Por meio de uma dinâmica com desenhos, interrogamos os alunos sobre onde eles imaginavam estar dentro de 10 anos. As respostas indicaram a dificuldade daqueles jovens em projetar um futuro que transcendesse sua realidade atual, na qual os obstáculos de formação eram visíveis. Acredita-se que a oportunidade de conhecer as políticas de cotas da UFBA e interagir com estudantes quilombolas e indígenas que já tinham conseguido ingressar na universidade contribuiu para ampliar a visão desses jovens com relação a projetos de vida.

Outro produto das práticas integradas em Ilha de Maré foi a organização de uma biblioteca infantil e infanto-juvenil na escola. Na parceria com o professor de língua portuguesa, o fomento à leitura revelou-se uma boa estratégia de empoderamento e emancipação social dos jovens. Por serem jovens negros e quilombolas, refletimos que a biblioteca deveria conter obras afrocentradas, produzidas por autores negros e que trouxessem conteúdos e abordagens antirracistas. A inauguração da biblioteca contou com a presença de alguns desses autores, o que, pela contação de suas histórias, despertou nos alunos a valorização das respectivas obras, assim como a reflexão sobre mecanismos históricos de exclusão social, como o racismo, e seus efeitos para a saúde. 
Ao longo dos quatro semestres nesse território, todas as atividades foram planejadas conjuntamente com os atores envolvidos: profissionais do Núcleo de Apoio à Saúde da Família (Nasf), a gerência da unidade, profissionais de saúde e professores e diretores da escola. Realizamos compartilhamento sistemático de encaminhamentos e avaliação processual durante todo o período. Com isso, foi possível desenvolver habilidades fundamentais ao sanitarista, como a capacidade de ter uma escuta sensível e um diálogo o mais simétrico possível, de modo a construir coletivamente e de forma democrática. Desenvolvemos também a habilidade de atuar em comunidade, com a sensibilidade cultural para reconhecer necessidades sociais de saúde e construir estratégias conjuntas de resolução de problemas.

No âmbito da USF, foram realizadas atividades de mobilização e informação em saúde focalizando dois agravos prevalentes em Ilha de Maré: albinismo e doença falciforme. Encontramos uma situação mais grave no caso desta, que culminou com a ocorrência de dois óbitos durante o período da disciplina. Esse fato, aliado à constatação da subnotificação do agravo e das fragilidades da assistência, suscitaram a realização de reuniões com profissionais de saúde, gestores do distrito e a gestão do Programa Municipal de Atenção Integral às Pessoas com Doença Falciforme do município, visando estabelecer pontes entre atores dentro e fora do território, responsabilizar os sujeitos envolvidos e discutir vias de enfrentamento dos problemas.

Vale ressaltar que a colaboração dos demais professores responsáveis pelos componentes curriculares do semestre (Política, Planejamento e Gestão e Educação e Comunicação em Saúde) foi crucial para o sucesso da atividade ao favorecer a ampliação da capacidade de compreensão e ação sobre o território, de forma articulada com a comunidade.

A avaliação do componente se deu sob a forma de portfólio reflexivo, no qual os alunos analisavam sua trajetória durante o semestre, articulando conceitos, vivências e avaliando sua atuação e seu processo de aprendizagem. Um dos relatos destacou a importância da vivência in loco para ampliar a compreensão acerca das desigualdades sociais, de seus impactos na vida das pessoas e das alternativas de superação: fazer parte por um pouco de tempo dessa comunidade me fez ver o quanto a desigualdade social é perversa, mas também o quanto eles podem driblar as adversidades (Discente 5).

A percepção quanto à importância da escuta e da comunicação horizontalizada na prática desenvolvida em Ilha de Maré foi outro aspecto ressaltado: toda [a] estruturação foi sendo construída a partir das visitas in loco, com a interação dos atores sociais desta comunidade por meio de uma comunicação polifônica que acolheu as diversas demandas identificadas [...]. A comunicação sempre se mostrou horizontalizada (Discente 8).

Outro depoimento problematizou o conceito de promoção da saúde, trazendo a ênfase numa visão culturalmente sensível:

pensar ações em saúde quase sempre é um desafio quando se considera o contex to sociocultural sobreo qual vive uma comunidade. Promover saúde é muito mais que simplesmente trazer a ideia de uma vida saudável para as pessoas, mas pode ser também empoderar o indivíduo na busca da sua identidade cultural. (Discente 3)

Ele finalizou seu relato trazendo uma visão mais ampliada da saúde e relativizando a ideia de intervenção de problemas: nosso principal objetivo em propor intervenções deve, acima de tudo, trazer para o território que sua situação de saúde abrange todo seu contexto de vida (Discente 3 ).

A avaliação positiva dos alunos e docentes que participaram do projeto em Maré e de outros envolvidos motivou sua continuidade no mesmo território por mais um semestre, mantendo-se o foco na promoção da saúde e nos elementos valorizados ao longo da experiência descrita: o olhar ampliado sobre a saúde e a valorização das práticas e saberes culturais locais.

\section{Considerações finais}

É interessante notar que, a despeito das diferenças em termos de trajetória e grau de institucionalização ou consolidação do ensino das CSH no campo da saúde coletiva, quando se compara a realidade da pós-graduação e da graduação, 
percebe-se que alguns desafios são coincidentes. É o caso, por exemplo, da tendência em promover uma formação mais instrumental, a qual é favorecida pela dificuldade em aprofundar os enfoques teóricos ou metodológicos das $\mathrm{CSH}$, tendo em vista, dentre outras, as limitações de carga-horária.

Não obstante, a CSG tem suas peculiaridades e, como tal, mesmo os desafios apontados, assim como as alternativas de enfrentamento identificadas, apresentam contornos singulares. Chama atenção, sobretudo, uma espécie de dinâmica na qual docentes e discentes parecem estar em permanente ebulição ou inquietação, sendo mais visível a pressão sobre os primeiros para encontrar alternativas aos problemas que se apresentam. 0 caso analisado corrobora também os achados de Ianni et al. (2014, p. 2305) no que diz respeito à disposição das novas gerações em afirmar o enfoque interdisciplinar ou romper com o que seus sujeitos identificaram como "conservadorismo disciplinar", intrínseco às ciências sociais "tradicionais".

Em que pesem esses indícios, cabe questionar se o projeto pedagógico que tem prevalecido na CSG reflete a complexidade desse campo seus objetos, seus atores, seus conflitos - e sua agenda contemporânea. É justamente com base na noção de campo, como propõe Madel Luz (2009), que conseguimos compreender melhor os tensionamentos históricos que têm marcado o projeto interdisciplinar na saúde coletiva. Em princípio, não há dificuldade em se reconhecer a multiplicidade ou coexistência de saberes e práticas presentes no campo. 0 problema reside na disputa pela hegemonia do poder simbólico entre os atores ou agentes que mobilizam os ditos saberes e práticas, os quais são hierarquicamente dispostos (Luz, 2009).

Romper com a hierarquização entre agentes e saberes está no cerne da concepção de conhecimento pluriuniversitário que propõe Boaventura de Sousa Santos - embora, aqui, o propósito seja bem mais ambicioso, uma vez que não se restringe à diversidade disciplinar, e sim de saberes, o que implica extrapolar os domínios da academia e relativizar sua autoridade.

Voltando à questão das escolhas, mais especificamente sobre a decisão de se adotar o trabalho na saúde como um elemento norteador do projeto de curso, cabem algumas ponderações. Preparar o aluno para o mundo do trabalho implica desenvolver também a capacidade de refletir sobre as estruturas, os processos e as relações sociais que aí se apresentam, numa rede complexa de relações cujo caráter histórico deve ser reconhecido. Além disso, mesmo quando se opta por privilegiar um tema central, é preciso estar atento para oportunizar, a partir dele, o debate e o aprendizado sobre um conjunto de outros temas que vêm assumindo protagonismo no mundo contemporâneo, a exemplo de gênero, relações raciais, questão ambiental etc.

Sem dúvida, é fundamental formar sanitaristas comprometidos com a luta pelo direito universal à saúde e a defesa de um SUS equitativo e de qualidade, que seja capaz de compor de forma competente seus quadros. Do mesmo modo, é igualmente desejável ampliar o horizonte de atuação desse futuro profissional, transcendendo tanto os muros da universidade quanto dos serviços. Em efeito, a CSG vem se revelando um lócus especialmente fértil para a experimentação de novas formas de conhecer e agir na educação e na saúde. Certamente, as CSH têm muito a contribuir nesse processo.

\section{Referências}

BRASIL. Ministério da Saúde. Conselho Nacional de Saúde. Resolução ${ }^{0} 544$, de 10 de março de 2017. Aprova a Nota Técnica ${ }^{0}{ }_{3}$, que contém recomendações do Conselho Nacional de Saúde à proposta de Diretrizes Curriculares Nacionais do curso de graduação em saúde coletiva. Diário Oficial da União, Brasília, DF,14 fev. 2018. Disponível em: <http://bit.ly/2GtHMDE>. Acesso em: 18 abr. 2019.

CANESQUI, A. M. Ciências sociais e saúde no Brasil. Rio de Janeiro: Hucitec, 2007.

FRIGOTTO, G.; CIAVATTA, M. Educar o trabalhador cidadão produtivo ou o ser humano emancipado? Trabalho, Educação e Saúde, Rio de Janeiro, v. 1, n. 1, p. 45-6o, 2003.

GADOTTI, M. Trabalho e educação numa perspectiva emancipatória. In: FÓRUM MUNDIAL DE EDUCAÇÃO PROFISSIONAL E TECNOLÓGICA, 2., 2012, Florianópolis. Anais... Brasília, DF: Ministério da Educação, 2012. Não paginado. 
IANNI, A. M. Z. et al. As ciências sociais e humanas em saúde na Abrasco: a construção de um pensamento social em saúde. Cadernos de Saúde Pública, Rio de Janeiro, v. 3o, n. 11, p. 2298-2308, 2014.

LUZ, M. T. Complexidade do campo da saúde coletiva: multidisciplinaridade, interdisciplinaridade e transdisciplinaridade de saberes e práticas: análise sócio-histórica de uma trajetória paradigmática. Saúde e Sociedade, São Paulo, v. 18, n. 2, p. 304-311, 2009.

LUZ, M. T. Especificidade da contribuição dos saberes e práticas das ciências sociais e humanas para a saúde. Saúde e Sociedade, São Paulo, v. 20, n. 1, p. 22-31, 2011.

MINAYO, M. C. S. Pós-graduação em saúde coletiva: um projeto em construção. Ciência \& Saúde Coletiva, Rio de Janeiro, v. 2, n. 1-2, p. 53-71, 1997.

NORMAN, G. Fifty years of medical education research: waves of migration. Medical Education, Oxford, v. 45, n. 8, p. 785-791, 2011.

NUNES, E. D. A trajetória das ciências sociais em saúde na América Latina: revisão da produção científica. Revista de Saúde Pública, São Paulo, v. 40, p. 64-72, 2006. Número especial.

NUNES, E. D. et al. O campo da saúde coletiva na perspectiva das disciplinas. Ciência \& Saúde Coletiva, Rio de Janeiro, v. 15, n. 4, p. 1917-1922, 2010.
SANTIAGO, A. R. F. Pedagogia crítica e educação emancipatória na escola pública: um diálogo entre Paulo Freire e Boaventura Santos. In: ANPED SUL: SEMINÁRIO DE PESQUISA EM EDUCAÇÃO DA REGIÃO SUL, 9., 2012, Caxias do Sul. Anais... Caxias do Sul: Anped Sul, 2012. Disponível em: <https://bit.ly/1SwCSF3>. Acesso em: 10 dez. 2018.

SANTOS, B. S. A universidade no século XXI: para uma reforma democrática e emancipatória da universidade. In: SANTOS, B. S.; ALMEIDA FILHO, N. (Org.). A universidade no século XXI: por uma universidade nova. Coimbra: Almedina, 2008. p. 13-106.

SANTOS, B. S. Por uma pedagogia do conflito. In: FREITAS, A. L. S.; MORAES, S. C. (Org.). Contra o desperdício da experiência: a pedagogia do conflito revisitada. Porto Alegre: Redes, 2009. p. 15-33.

TRAD, L. A. B. Temas e enfoques contemporâneos nas ciências sociais e humanas no Brasil: expressões e tendências refletidas no V Congresso da área. Cadernos de Saúde Pública, Rio de Janeiro, v. 28, n. 12, p. 2373-2379, 2012.

TRAD, L. A. B. et al. Perfil e contribuições das ciências humanas e sociais no campo da saúde coletiva: pesquisa, ensino e extensão: foco nos programas de pós-graduação. Salvador: ISC Ufba, 2018. Relatório de pesquisa. Mimeo.

\section{Contribuição dos autores}

Trad definiu a estrutura do artigo e os argumentos nucleares do texto, integrando as contribuições das diferentes autoras. Mota elaborou o relato de experiência. López apresentou reflexões específicas sobre algumas questões abordadas no artigo. Todas as autoras colaboraram com a redação e revisão final do manuscrito.

Recebido: 14/02/2019

Aprovado: 21/03/2019 